\title{
Adult Acute Monocytic Leukemia
}

National Cancer Institute

\section{Source}

National Cancer Institute. Adult Acute Monocytic Leukemia. NCI Thesaurus. Code C8263.

An acute monocytic leukemia occurring in adults. 